\title{
What's New in Acute Respiratory Distress Syndrome in Infants and Children
}

\author{
G. Zobel, S. RöDl, H.M. Grubbauer, M. TroP
}

Acute respiratory distress syndrome (ARDS) was first described in 1967 by Asbough et al. as a clinical syndrome that occurs 24 to 48 hours after a direct or indirect lung injury [1]. It is characterised by dyspnea, tachypnea, hypoxemia refractory to oxygen therapy, decreased lung compliance, and diffuse alveolar infiltrates on chest X-ray. ARDS is a rare disorder in childhood. The incidence varies from 0.8 to $4.4 \%$ among all admissions to the paediatric ICU [2-8]. ARDS is a significant cause of morbidity in critically ill children. While therapeutic interventions remain supportive, the management of evolving acute lung injury is often a controversial issue in the paediatric ICU. There has been significant progress in our understanding of the pathophysiology of acute lung injury and in our understanding of how lung injury is often amplified in the course of mechanical support. This understanding has led to a strategic shift in ventilation style principally geared to optimally recruiting and then maintaining end-expiratory lung volume, preventing the traumatic cycle of derecruitment-recruitment, and finally, limiting alveolar stretching during tidal inflation.

\section{Ventilator induced lung injury (VILI)}

The negative impact of mechanical ventilation on the disease process in acute lung injury has been assumed for years, based on animal studies. These studies showed that ventilation with the use of large tidal volumes caused the disruption of pulmonary epithelium and endothelium, lung inflammation, atelectasis, hypoxemia, and the release of inflammatory mediators [9-13]. Thus the traditional approach to mechanical ventilation may exacerbate or perpetuate lung injury in patients with ARDS. Protecting the "normal" population of compliant alveoli within heterogeneous lung necessitates limiting transalveolar pressure to 30-35 $\mathrm{cm} \mathrm{H}_{2} \mathrm{O}$. Beyond this limit, it is important to recognize the significance of the upper inflection point in the pressure/volume (P/V) curve. When endexpiratory lung volume is appropriately optimized, avoidance of the upper inflection point generally requires limiting volume-cycled breaths to $4-8 \mathrm{ml} / \mathrm{kg}$. A similar tidal volume may be targeted when the transalveolar pressure excursion is limited by fixing end-expiratory and end-inspiratory pressures. This excursion should be in the general range of $20 \mathrm{~cm} \mathrm{H}_{2} \mathrm{O}$. 


\section{Permissive hypercapnia (PHC)}

In 1990 Hickling et al. introduced the concept of low volume pressure limited ventilation with permissive hypercapnia for patients with severe ARDS [14]. This ventilatory strategy avoided further ventilator induced lung damage while moderate or even severe hypercapnia was well tolerated by the critically ill patients. In this uncontrolled study in patients with severe ARDS Hickling showed that the hospital mortality rate was significantly lower than predicted by Apache II (16\% versus $39.6 \%)$.

In a recent study on ARDS patients ventilation with lower tidal volumes (6 $\mathrm{ml} / \mathrm{kg}$ ) was compared with traditional tidal volumes $(12 \mathrm{ml} / \mathrm{kg})$ [15]. The primary outcome was death before a patient was discharged home and was breathing without assistance. The second primary outcome was the number of days without ventilator use from day 1 to day 28 . The trial was stopped after enrolment of 861 patients because mortality was lower in the group treated with lower tidal volumes $(31 \%$ vs. $39.8 \%, p<0.01)$, and the number of days without ventilator use was greater in this group $(12 \pm 11$ vs. $10 \pm 11, p<0.01)$. The authors concluded that in patients with acute lung injury and ARDS mechanical ventilation with lower tidal volume than is traditionally applied results in decreased mortality and increases the number of days without ventilator use.

There are only few reports on controlled hypoventilation in paediatric patients with ARDS [16-18]. A randomized trial of permissive hypercapnia in preterm infants showed that a ventilatory strategy of permissive hypercapnia is feasible, seems safe, and may reduce the duration of assisted ventilation [19]. There were no differences in mortality, air leaks, intraventricular haemorrhage, periventricular leukomalacia, retinopathy of prematurity, or patent ductus arteriosus.

We used this ventilatory strategy with tidal volumes of $8 \mathrm{ml} / \mathrm{kg}$ in 20 paediatric patients with ARDS or acute lung injury. This strategy resulted in $\mathrm{PaCO}_{2}$ values between 60 and $80 \mathrm{mmHg}$ associated with $\mathrm{pH}$ values between 7.25 and 7.35. The overall mortality in these 20 patients was $30 \%$. Baro-volutrauma was observed in 6 patients. Additional therapies included NO inhalation $(n=17)$, surfactant therapy $(n=11)$, and ECMO support $(n=5)$.

\section{Recruitment manoeuvres}

There is now further evidence from experimental data that lung recruitment during small tidal volume ventilation allows ventilation on the deflation limb of the pressure-volume curve of the lungs at a PEEP $<$ Pinflex [20]. This strategy minimizes lung injury and ensures a lower PEEP, which may minimize the detrimental consequences of high volume ventilation. These sustained inflation manoeuvres for alveolar recruitment are safe in adult patients with ARDS resulting in improved oxygenation [21]. In a recent abstract Gaudencio et al. reported that 
lung recruitment manoeuvres with PEEP values between 30 and $40 \mathrm{~cm} \mathrm{H}_{2} \mathrm{O}$ improved gas exchange in 4 paediatric patients with ARDS without negative haemodynamic effects [22].

\section{High frequency oscillation (HFO)}

This form of ventilatory support does not create normal bulk flow ventilatory patterns through changes in lung volume and delivered pressure, but rather maintains lung recruitment via a steady inflating pressure (generally 15 to 30 $\mathrm{cm} \mathrm{H}_{2} \mathrm{O}$ ) around which high-frequency oscillations (range between 4 and $15 \mathrm{~Hz}$ with an amplitude of 20 to $60 \mathrm{~cm} \mathrm{H}_{2} \mathrm{O}$ ) generate alveolar ventilation. Tidal volumes are smaller than anatomic deadspace resulting in lower peak alveolar pressures than observed during CMV. Mean airway pressure during HFO is most commonly set above closing pressure and lung volume is maintained steadily without deflation. During HFO lung volume will not travel along the deflation curve to the point of derecruitment. Therefore, the lung may be optimally protected from the stress of cyclic derecruitment that occurs during CMV.

HFO has been widely studied in animal models of acute lung injury [23-25]. It has been shown that HFO improves oxygenation, minimizes histopathologic alterations of acute lung injury when compared to CMV, reduces activated pulmonary neutrophils, and reduces important inflammatory mediators [26, 27]. There is evidence that HFO may be most effective when used early in the course of acute respiratory failure. An optimal lung volume is best achieved with an aggressive initial volume recruitment strategy with relatively high Paw values. There is an important gradient in both peak and mean Paw values from the ventilator to alveolus.

In 1994 Arnold et al. published their experience with high frequency oscillation and conventional mechanical ventilation in 58 paediatric patients with acute respiratory failure [28]. In their prospective, randomized study with crossover design they used a high volume HFO strategy to optimise lung recruitment. Although they used higher Paw during HFO than during CMV the barotrauma frequency was lower during HFO. Of 29 patients enrolled to the HFO group 17 patients $(58 \%)$ showed a good response to $\mathrm{HFO}$ and one patient died. However, 11 patients (38\%) crossed over to CMV and $9(82 \%)$ subsequently died. The authors concluded that early institution of a high lung volume strategy using HFO would be the ideal ventilatory approach in paediatric patients with ARDS. Nonresponders to this ventilatory strategy should be considered for alternative approaches such as extracorporeal life support. We used HFO as a rescue therapy in 7 patients with ARDS when conventional respiratory support had failed. In this situation HFO with a high volume strategy improved gas exchange in only one patient. The use of HFO as a rescue strategy when all other therapeutic steps have failed might explain the disappointing results with HFO in our patients. 


\section{Partial liquid ventilation (PLV)}

The rationale for mechanical ventilation in acute lung injury is to apply a PEEP to prevent end-expiratory collapse of collapsible alveoli and to select a tidal volume to limit overdistension of lung units [29]. Another therapeutic option would be to eliminate the increased forces acting at the air-liquid interface in the acutely damaged lung by filling the lungs with a perfluorochemical liquid [30].

Perfluorocarbon liquids are organic hydrogen molecules in which carbonbound hydrogen atoms are replaced by fluorine atoms. They are biologically inert, non-biotransformable and immiscible in both aqueous and lipid media. Perfluorocarbon liquids are absorbed minimally by the respiratory epithelium, and are eliminated by evaporation through the lungs. Oxygenated perfluorocarbon liquids have the ability to lower surface tension in surfactant-deficient lungs, to increase functional residual capacity (FRC), and are able to dissolve large amounts of respiratory gases.

In 1991 Fuhrman et al. introduced the technique of perfluorocarbon-associated gas exchange or PLV [31]. This new technique combined liquid ventilation at functional residual capacity and tidal gas volume ventilation using a conventional ventilator. Meanwhile a number of experimental studies have shown that PLV significantly improves oxygenation, lung mechanics, decreases further alveolar damage and decreases serum tumour necrosis factor-a concentration in acute lung injury [32-38]. Most investigators filled up the lung with PFC-liquid at FRC level $(30 \mathrm{~mL} / \mathrm{kg})$ and used volume-controlled mechanical ventilation with a tidal volume $>15 \mathrm{~mL} / \mathrm{kg}$ and a PEEP level between 2 and $6 \mathrm{~cm} \mathrm{H}_{2} \mathrm{O}$ in both the PLV as well as the control groups.

Greenspan and colleagues reported on the first human liquid ventilation experience in preterm infants [39]. Meanwhile the technique of PLV has been studied in neonatal, paediatric, and adult patients [40-42]. Leach et al. reported that partial liquid ventilation resulted in significant improvement in oxygenation in 13 premature infants with RDS after conventional treatment, including surfactant therapy, had failed [40]. A paediatric study in children with ARDS was stopped at enrolment of 182 patients, due to design problems of the study. Series of case reports have shown that partial liquid ventilation in adults is well tolerated and has resulted in improvement in oxygenation. A phase 2 clinical study included 90 patients, 65 of whom were treated with partial liquid ventilation [43]. Overall, the results from this study demonstrated no statistical differences between the treated and control patients. A multicenter study on PLV in adults with ARDS is running involving centres in the USA, Canada, and Europe. 


\section{Extracorporeal membrane oxygenation (ECMO)}

Rescue therapy with ECMO for patients with severe refractory hypoxia remains of unclear benefit outside the neonatal population. A recent retrospective review by Masiakos et al. showed an overall survival rate of 53\% for non-neonatal acute respiratory failure and ECMO support [44]. ELSO registry from July 1999 reported similar survival data of paediatric patients with acute respiratory failure [45]. MOSF and longer time on mechanical ventilation before ECMO predicted worse outcome, whereas duration of ECMO did not influence outcome. In another recent publication from a single institution Swaniker et al. reported an overall lung recovery in paediatric patients with acute respiratory failure of $77 \%$ and a hospital survival rate of $71 \%$ [46]. Zahraa et al. reported that the outcome of paediatric patients with acute respiratory failure supported by veno-arterial or veno-venous extracorporeal lung support was comparable (survival rate: 55.8\% vs. $60 \%$ ) and that neurological complications were not different between patients supported by veno-arterial or venous-venous bypass [47].

In our series of 11 patients 8 were supported by the veno-venous technique, 1 by veno-arterial technique, and 2 patients switched from veno-venous to venoarterial bypass. The overall survival rate was $55 \%$.

\section{ARDS-Adjuncts}

\section{Surfactant}

ARDS is associated with a quantitative decrease in total lung surfactant, changes in phospholipid/surfactant protein ratios, and surfactant inhibition from pathologic events in the alveolar space. While surfactant replacement therapy is well established in preterm and term infants, this therapy remains unproven beyond the neonatal period [48, 49]. In 1999 Wilson et al. showed in a multi-institutional, prospective, randomised, controlled study in 42 children with acute hypoxemic respiratory failure that patients who received surfactant therapy demonstrated rapid improvement in oxygenation, and, on average, were extubated 4.2 days (32\%) sooner and spent 5 fewer days (30\%) in paediatric intensive care than the control patients [50]. There was no difference in mortality rate or overall hospital stay. In the surfactant group 2 patients were on HFO, one patient inhaled NO, and one patient was on ECMO support, whereas in the control group 6 patients were on HFO, 2 inhaled NO, and one patient was on ECMO support. The overall mortality rate in this study was $11.9 \%$, and only one death was from progressive respiratory failure. In this study 8 of 21 patients received a single dose of surfactant, and 10 patients a second dose. After the second dose the patients did not improve acutely. This is in contrast to the neonatal experience, where multiple doses have been shown to be beneficial. However, this study was not designed to compare single versus multiple doses of surfactant. 


\section{Inhaled nitric oxide (NO)}

Acute respiratory failure is often associated with severe pulmonary ventilationperfusion mismatch and pulmonary hypertension. Conventional intravenous vasodilator therapy results in a reduction of both the pulmonary and systemic pressures and worsening of gas exchange caused by a nonselective vasodilation of pulmonary arteries. Inhaled NO is a selective pulmonary vasodilator without any systemic side effects [51]. Inhaled NO rapidly diffuses from the alveoli of ventilated regions to the surrounding tissue causing relaxation of vascular smooth muscle cells. In the blood stream NO is rapidly bound to haemoglobin forming methemoglobin. In 1993 Rossaint et al. reported that inhaled NO reduces the pulmonary artery pressure and increases arterial oxygenation by improving ventilation-perfusion mismatch without producing systemic vasodilation [52]. Abman et al. reported their experience with inhaled NO in 10 paediatric patients with ARDS and 7 with severe viral pneumonias [53]. Inhalation of 20 ppm NO increased $\mathrm{PaO}_{2}$ levels within 30 minutes by approximately $50 \%$ in each group. In addition mean pulmonary artery pressure was lowered from $42 \pm$ $6 \mathrm{mmHg}$ to $31 \pm 6 \mathrm{mmHg}(p<0.01)$ and intrapulmonary shunt fraction decreased from $39 \pm 7 \%$ to $32 \pm 7 \%(p<0.01)$. However, the mortality rate of $50 \%$ in the 10 children with ARDS was quite high.

Despite acute physiologic effects, it remains uncertain whether improved oxygenation and pulmonary haemodynamics during iNO therapy are "cosmetic" or actually translate to significant benefits in long-term outcomes. Recent multicenter, randomized trials of iNO therapy have consistently demonstrated improved oxygenation in adults with ARDS, but have not shown a reduction in mortality or morbidity [54]. Recently a randomized multicenter study on iNO therapy in paediatric patients with acute hypoxemic respiratory failure was published by Dobyns et al. [55]. One hundred and eight patients were enrolled for the study. Patients were randomized to iNO $(10 \mathrm{ppm})$ or placebo treatment groups throughout a 3 day study period. Treatment failure defined as OI $>25$ for $6 \mathrm{hrs}$ or OI $>40$ for $3 \mathrm{hrs}$ was the primary study endpoint. Progressive haemodynamic deterioration, metabolic acidosis, methemoglobinemia or high $\mathrm{NO}_{2}$ levels were criteria to exit the study and to receive "rescue" therapy. Oxygenation improved over time in both groups, but the response was greater with iNO treatment at 4 and $12 \mathrm{hrs}$. The rate of treatment failure remained greater in the control group over the first 24 hours. Despite this acute response, the proportion of patients who met treatment failure criteria was not different over the 3-day study. Mortality was not different between both groups (43\%), but since cross-over was allowed, this mortality was not an end point of this study. During prolonged therapy the failure rate was reduced in the iNO group patients. The authors concluded that iNO causes an acute improvement in oxygenation in children with severe acute hypoxemic respiratory failure. Two subgroups (immunocompromised and an entry OI > 25) appear to have a more sustained improvement in oxygenation, and the authors speculated that these subgroups may benefit from prolonged therapy. 
In a recent paper Ream et al. showed that inhaled NO at doses $<5 \mathrm{ppm}$ improved oxygenation and to a lesser extent ventilation of $62 \%$ of children with acute, hypoxic respiratory failure [56]. Mortality was not influenced by prolonged inhalation of $\mathrm{NO}$ at doses $<20 \mathrm{ppm}$. The unpredictable response of patients necessitates individualized dosing of inhaled NO, starting at concentrations of $<1 \mathrm{ppm}$.

We used inhaled NO in 17 paediatric patients with ARDS. As shown in Table 1 we observed an acute increase in arterial oxygen saturation in 59\% of the patients. However, despite this initial improvement in oxygenation, there was no significant difference in duration of mechanical ventilation, ECMO-support, and mortality rate between initial iNO responders and nonresponders.

Table 1. Inhaled NO in pediatric patients with ARDS $(n=17)$

\begin{tabular}{|c|c|c|}
\hline & Responder & Nonresponder \\
\hline No. of patients & 10 & 7 \\
\hline Duration of $M V(d)$ & $22 \pm 5$ & $26 \pm 11$ \\
\hline iNO (ppm) & $4 \pm 0.8$ & $9.5 \pm 2.1 *$ \\
\hline$\Delta \mathrm{SpO}_{2}(\%)$ & $9.2 \pm 1.7$ & $0.28 \pm 0.89 *$ \\
\hline \multicolumn{3}{|l|}{ ARDS (n) } \\
\hline Primary & 5 & 5 \\
\hline Secondary & 5 & 2 \\
\hline LIS & $3.2 \pm 0.15$ & $3.3 \pm 0.2$ \\
\hline $\mathrm{OI}$ & $29.4 \pm 3.8$ & $31.1 \pm 5$ \\
\hline VI & $50.2 \pm 5.5$ & $45 \pm 6.5$ \\
\hline Immunosuppression (n) & 2 & 3 \\
\hline ECMO-support (n) & 4 & 2 \\
\hline Mortality rate (\%) & 40 & 43 \\
\hline
\end{tabular}

Responder $\left(\Delta \mathrm{SpO}_{2}>5 \%\right)$; Nonresponder $\left(\Delta \mathrm{SpO}_{2}<5 \%\right)$; LIS = lung injury score; OI = oxygenation index $\left(\mathrm{Paw}^{*} \mathrm{FiO}_{2} *\right.$ $\left.100 / \mathrm{PaO}_{2}\right) ; \mathrm{VI}=$ ventilation index $\left(\mathrm{PaCO}_{2} * \mathrm{PIP} * \mathrm{RR} / 1000\right)$

\section{Prone position}

There is now some evidence that turning a hypoxemic patient with ARDS from supine to prone position may improve oxygenation [57]. The proposed mechanisms for this improvement are an increase in FRC, change in regional diaphragm motion, redistribution of blood flow to less injured lung units and improved secretion clearance. Studies of experimental lung injury have shown that when turning to the prone position, preferential perfusion does not shift to the ventral part of the lung and that edema is more uniformly distributed along the gravitational axis. There was also no change in FRC or regional diaphragm movement. The explanation for the decreased shunting seen with prone position 
seems to be that the gravitational distribution of pleural pressure is much more uniform in the prone position [58]. In the supine position the gravitational forces result in pleural pressure becoming positive in the dependent lung regions and dorsal lung units are below closing volume. This finding suggests that transpulmonary pressure may not exceed airway pressure in this region, resulting in lung collapse. The gravitational pleural pressure differences in the thorax are much less in the prone position, resulting in less of the lung below closing volume and decreased shunt. Recently Curley et al. demonstrated in a prospective case series in paediatric patients with acute lung injury that oxygenation improved without serious iatrogenic injury after prone positioning [59]. On the basis of their clinical findings the authors proposed a prospective randomized study investigating the effect of early and repeated prone positioning on clinical outcomes in paediatric patients with acute lung injury.

\section{Outcome in ARDS}

ARDS is a syndrome with many different aetiologies and the outcome will be greatly influenced by the underlying cause. For instance, the mortality in ARDS associated with sepsis is higher than that associated with trauma or patients with single system lung disease without other organ dysfunction. In a published series of adult ARDS patients hypoxemia was the primary cause of death in only $16 \%$ of patients, the rest being sepsis and multiorgan failure. Therefore the ability to demonstrate improved oxygenation alone using a non-conventional approach would be unlikely to have a significant impact on outcome unless it could be shown that it either decreases the amount of lung injury or shortens the duration of ventilator support. There is now experimental data showing that lung overdistension results in the release of cytokines which may be responsible for multiorgan injury and dysfunction [60]. This provides a further rational for the use of ventilator strategies which prevent these events.

Most of the published data on ARDS in paediatric patients are small series reporting mortality rates between 40 and $70 \%$ [2-6, 8, 61]. A multicenter prospective study carried out on over 400 paediatric patients with acute respiratory failure, collected over a 1-year period, who required the combination of $\mathrm{FiO}_{2}>0.5$ and PEEP $>6 \mathrm{~cm} \mathrm{H}_{2} \mathrm{O}$ for more than 12 hours, reported a mortality rate of $43 \%$ [62]. We treated 61 paediatric patients with ARDS over a time period of 16 years, 17 children between 1983 and 1990 with a conventional ventilatory approach and 44 children treated between 1991 and 2000 using a more lung protective approach. Mortality rate in patients treated before 1990 was $59 \%$ and the mortality in patients treated after 1990 was 27\% (Fig. 1). 


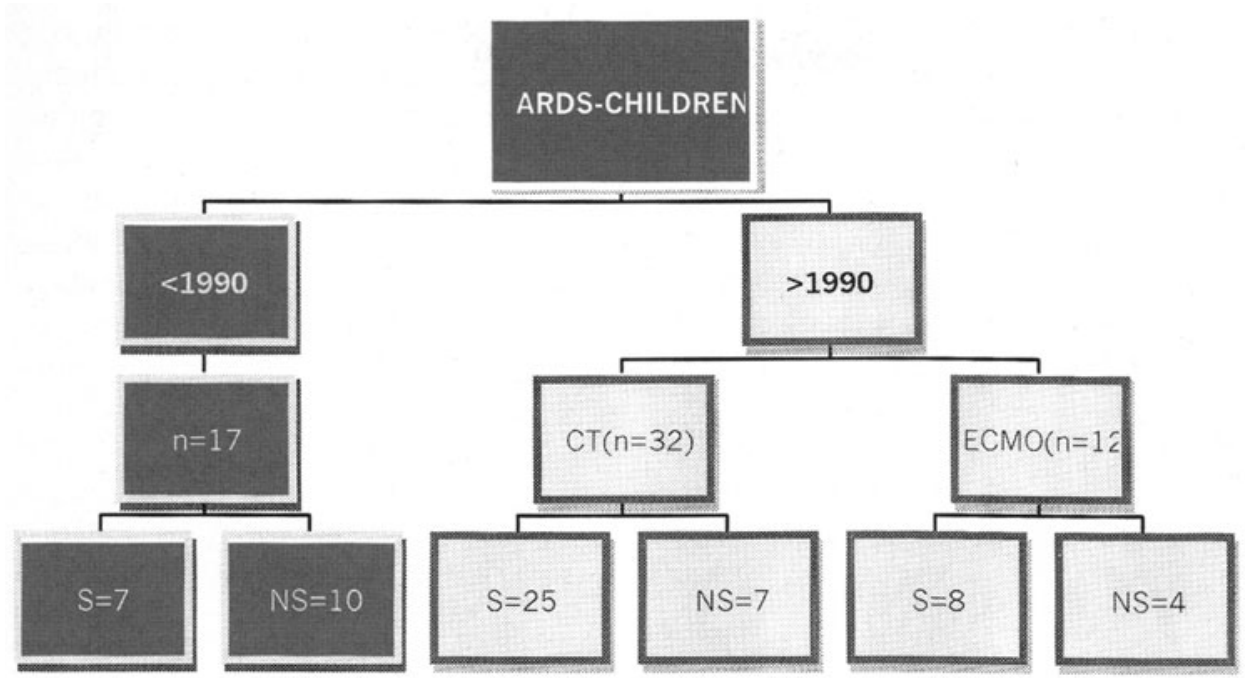

Mortality rate: $59 \%$

Mortality rate: $27 \%$

Fig. 1. Prognosis of ARDS in children under conventional mechanical ventilation and "lung protective" ventilation

CT: conventional therapy; ECMO: extracorporeal membrane oxygenation; S: responders; NS: nonresponders

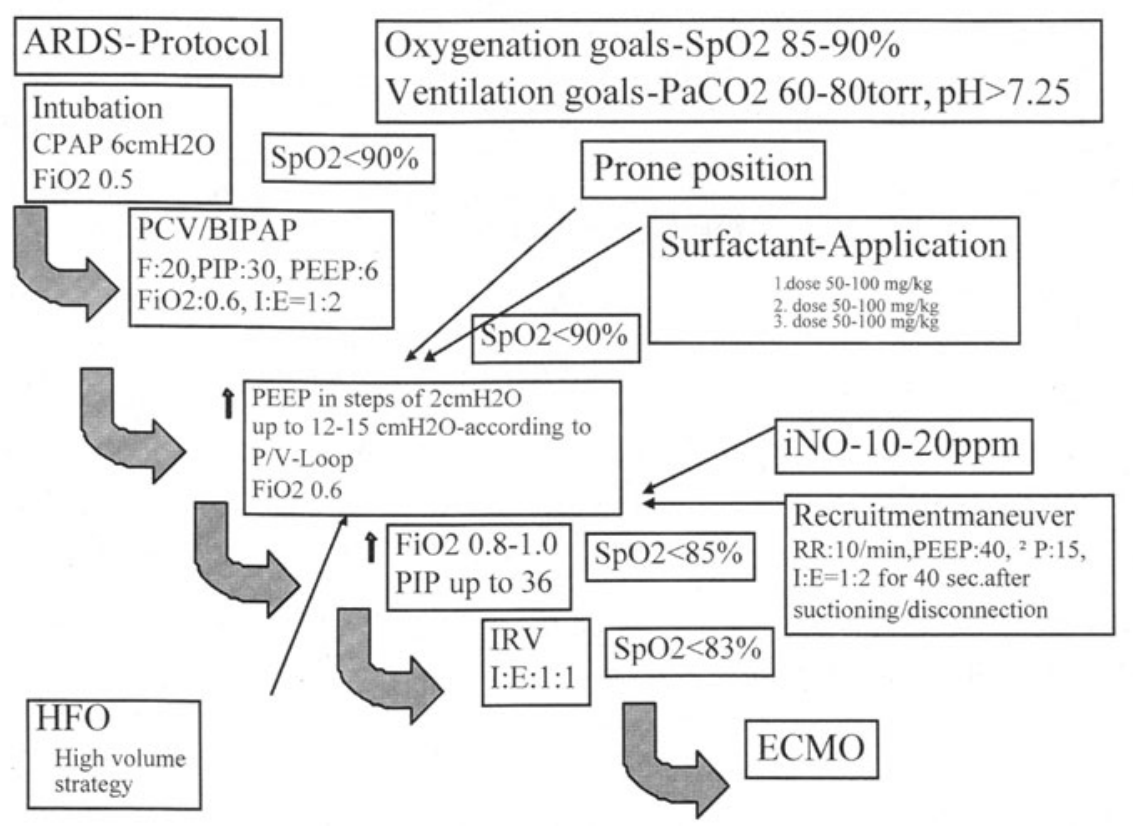

Fig. 2. Therapeutic algorithm for children with ARDS 


\section{Conclusion}

On the basis of experimental and clinical data we now use a treatment algorithm for paediatric patients with ARDS (Fig. 2) and we hope that using this algorithm will help us to decrease the mortality rate of children with ARDS below $20 \%$ in the next years.

\section{References}

1. Asbough DG, Bigelow DB, Petty TL et al (1967) Acute respiratory distress in adults. Lancet ii:319-323

2. Holbrook PR, Taylor G, Pollack MM et al (1980) Adult respiratory distress syndrome in children. Pediatr Clin North Am 27:677-685

3. Pfenninger J, Gerber A, Tschappeler $\mathrm{H}$ et al (1982) Adult respiratory distress syndrome in children. J Pediatr 101:352-357

4. Lyrene RK, Truog WE (1981) Adult respiratory distress syndrome in a pediatric intensive care unit: Predisposing conditions, clinical course, and outcome. Pediatrics 67:790-795

5. Timmons OD, Dean JM, Vernon DD (1991) Mortality rates and prognostic variables in children with adult respiratory distress syndrome. J Pediatr 119:896-899

6. DeBruin W, Notterman DA, Magid M et al (1992) Acute hypoxemic respiratory failure in infants and children: Clinical and pathologic characteristics. Crit Care Med 20:1223-1234

7. Royall JA, Levin DL (1988) Adult respiratory distress syndrome in pediatric patients. I: Clinical aspects, pathophysiology, pathology and mechanisms of lung injury. J Pediatr 112: $169-180$

8. Davis SL, Furman DP, Costarino AT et al (1993) Adult respiratory distress syndrome in children: Associated disease, clinical course, and predictors of death. J Pediatr 123:35-45

9. Matthay MA, Folkesson HG, Campagna A et al (1993) Alveolar epithelial barrier and acute lung injury. New Horizons 1:613-622

10. Kolobow T, Moretti MP, Fumagalli R et al (1987) Severe impairment in lung function induced by high peak airway pressure during mechanical ventilation. An experimental study. Am Rev Respir Dis 135:312-315

11. Dreyfuss D, Soler P, Basset G et al (1988) High inflation pressure pulmonary edema: Respective effects of high airway pressure, high tidal volume, and positive end-expiratory pressure. Am Rev Respir Dis 137:1159-1164

12. Tremblay L, Valenza F, Ribeiro SP et al (1997) Injurious ventilatory strategies increase cytokines and c-fos m-RNA expression in an isolated rat lung model. J Clin Invest 99:944-952

13. Dreyfuss D, Saumon G (1998) Ventilator-induced lung injury. Am J Respir Crit Care Med 157:294-323

14. Hickling KG, Henderson SJ, Jackson R (1990) Low mortality associated with low volume pressure limited ventilation with permissive hypercapnia in severe adult respiratory distress syndrome. Intensive Care Med 16:372-377

15. The Acute Respiratory Distress Syndrome Network (2000) Ventilation with lower tidal volumes as compared with traditional tidal volumes for acute lung injury and the acute respiratory distress syndrome. N Engl J Med 342:1301-1308

16. Sheridan RL, Kacmarek RM, McEttrick MM et al (1995) Permissive hypercapnia as a ventilatory strategy in burned children: Effect on barotrauma, pneumonia, and mortality. J Trauma 39:854-859

17. Tibby SM, Cheema IU, Sekaran D et al (1999) Use of permissive hypercapnia in the ventilation of infants with respiratory syncytial virus. Eur J Pediatr 158:42-45

18. Trop M, Zobel G, Waniek E et al (1997) Controlled mechanical hypoventilation in pediatric burn patients as treatment of acute respiratory distress syndrome. Burns 23:166-169 
19. Mariani G, Cifuentes J, Carlo WA (1999) Randomized trial of permissive hypercapnia in preterm infants. Pediatrics 104:1082-1088

20. Rimensberger PC, Pristine G, Mullen BM et al (1999) Lung recruitment during small tidal volume ventilation allows minimal positive end-expiratory pressure without augmenting lung injury. Crit Care Med 27:1940-1945

21. Lapinsky SE, Aubin M, Mehta S et al (1999) Safety and efficacy of a sustained inflation for alveolar recruitment in adults with respiratory failure. Intensive Care Med 25:1297-1301

22. Gaudencio AMAS, Troster EJ, Faria LF et al (2000) Effects of a lung recruitment maneuver keeping PEEP before and after L-Pflex on gas exchange in chilled ARDS patients. Critical Care 4[Suppl 1]:S67

23. Hamilton PP, Onayemi A, Smith JA et al (1983) Comparison of conventional and high-frequency ventilation: Oxygenation and lung pathology. J Appl Physiol 55:131-138

24. DeLemos RA, Coalson JJ, Gerstmann DR et al (1987) Ventilatory management of infant baboons with hyaline membrane disease: The use of high frequency ventilation. Pediatr Res 21:594-602

25. McCulloch PR, Forkert PG, Froese AB (1988) Lung volume maintenance during HFO in surfactant deficient rabbits. Am rev Respir Dis 137:1185-1192

26. Sugiura M, McCulloch $P$, Wren $S$ et al (1994) Ventilator pattern influences neutrophil influx and activation in atelectasis prone rabbit lung. J Appl Physiol 77:1355-1365

27. Imai Y, Kawano T, Miyasaka K et al (1994) Inflammatory chemical mediators during conventional and during high frequency oscillatory ventilation. Am J Respir Crit Care Med 150: $1550-1554$

28. Arnold JH, Hanson JH, Toro-Figuero LO et al (1994) Prospective, randomized comparison of high-frequency oscillatory ventilation and conventional mechanical ventilation in pediatric respiratory failure. Crit Care Med 22:1530-1539

29. Lachmann B (1992) Open up the lung and keep the lung open. Intensive Care Med 18: 319-321

30. Lachmann B, Verbrugge S (1996) Liquid ventilation. Current Opinion in Critical Care 2: 60-66

31. Fuhrman BP, Paczan PR, DeFrancisis M (1991) Perfluorocarbon-associated gas exchange. Crit Care Med 19:712-722

32. Tütüncü AS, Faithfull NS, Lachmann BL (1993) Intratracheal perfluorocarbon administration combined with mechanical ventilation in experimental respiratory distress syndrome: Dosedependent improvement of gas exchange. Crit Care Med 21:962-969

33. Tütüncü AS, Faithfull NS, Lachmann BL (1993) Comparison of ventilatory support with intratracheal perfluorocarbon administration and conventional mechanical ventilation in animals with acute respiratory failure. Am Rev Respir Dis 148:785-792

34. Leach CL, Fuhrman BP, Morin III FC et al (1993) Perfluorocarbon-associated gas exchange (partial liquid ventilation) in respiratory distress syndrome: A prospective, randomized, controlled study. Crit Care Med 21:1270-1278

35. Papo MC, Paczan PR, Fuhrman BP et al (1996) Perfluorocarbon-associated gas exchange improves oxygenation, lung mechanics, and survival in a model of adult respiratory distress syndrome. Crit Care Med 24:466-474

36. Hirschl RB, Tooley R, Parent AC et al (1996) Evaluation of gas exchange, pulmonary compliance, and lung injury during total and partial liquid ventilation in the acute respiratory distress syndrome. Crit Care Med 24:1001-1008

37. Quintel M, Heine M, Hirschl RB et al (1998) Effects of partial liquid ventilation on lung injury in a model of acute respiratory failure: A histologic and morphometric analysis. Crit Care Med 26:833-843

38. Rotta AT, Gunnarsson B, Hernan LJ et al (1999) Partial liquid ventilation influences pulmonary histopathology in an animal model of acute lung injury. J Crit Care 14:84-92

39. Greenspan JS, Wolfson MR, Rubinstein SD et al (1990) Liquid ventilation of human preterm neonates. J Pediatr 117:106-111 
40. Leach CL, Greenspan JS, Rubinstein SD et al (1996) Partial liquid ventilation with perflubron in premature infants with severe respiratory distress syndrome. N Engl J Med 335:761-767

41. Gauger PG, Pranikoff T, Schreiner RJ et al (1996) Initial experience with partial liquid ventilation in pediatric patients with acute respiratory distress syndrome. Crit Care Med 24:16-22

42. Hirschl R, Pranikoff T, Wise C et al (1996) Initial experience with partial liquid ventilation in adult patients with acute respiratory distress syndrome. JAMA 275:383-389

43. Bartlett R, Croce M, Hirschl RB et al (1997) A phase II randomized, controlled trial of partial liquid ventilation in adult patients with acute hypoxemic respiratory failure. Crit Care Med 25:A135

44. Masiakos PT, Islam S, Doody DP et al (1999) Extracorporeal membrane oxygenation for nonneonatal respiratory failure. Arch Surg 134:375-379

45. ELSO report 1999, Ann Arbor, Michigan

46. Swaniker F, Kolla S, Moler F et al (2000) Extracorporeal life support for 128 pediatric patients with respiratory failure. J Pediatr Surg 35:197-202

47. Zahraa JN, Moler FW, Annich GM et al (2000) Venovenous versus venoarterial extracorporeal life support for pediatric respiratory failure: Are there differences in survival and acute complications? Crit Care Med 28:521-525

48. Long W, Corbet A, Cotton R et al (1991) A controlled trial of synthetic surfactant in infants weighing $1250 \mathrm{~g}$ or more with respiratory distress syndrome. The American Exosurf neonatal study group I, and the Canadian Exosurf neonatal study group. N Engl J Med 352:1696-1703

49. Auten RL, Notter RH, Kendig JW et al (1991) Surfactant treatment of full-term newborns with respiratory failure. Pediatrics 87:101-107

50. Wilson DF, Zaritsky A, Bauman LA et al (1999) Instillation of calf lung surfactant extract (calfactant) is beneficial in pediatric acute hypoxemic respiratory failure. Crit Care Med 27:188-195

51. Zapol WM, Hurford WE (1993) Inhaled nitric oxide in the adult respiratory distress syndrome and other lung diseases. New Horizons 1:638-650

52. Rossaint R, Falke KJ, Lopez F et al (1993) Inhaled nitric oxide in adult respiratory distress syndrome. N Engl J Med 328:399-405

53. Abman SH, Griebel JL, Parker DK et al (1994) Acute effects of inhaled nitric oxide in children with severe hypoxemic respiratory failure. J Pediatr 124:881-888

54. Dellinger RP, Zimmermann JL, Taylor RW et al (1998) Effects of inhaled NO in patients with ARDS: Results of a randomized phase II trial. Crit Care Med 26:15-23

55. Dobyns EL, Cornfield DN, Anas NG et al (1999) Multicenter randomized trial of the effects of inhaled NO therapy on gas exchange in children with acute hypoxemic respiratory failure. J Pediatr 134:406-412

56. Ream RS, Hauver JF, Lynch-RE et al (1999) Low-dose inhaled nitric oxide improves the oxygenation and ventilation of infants and children with acute, hypoxemic respiratory failure. Crit Care Med 27:989-996

57. Blanch L, Mancebo J, Perez M et al (1997) Short-term effects or prone position in critically ill patients with acute respiratory distress syndrome. Intensive Care Med 23:1033-1039

58. Lamm WJ, Graham MM, Albert RK (1994) Mechanism by which the prone position improves oxygenation in acute lung injury. Am J Respir Crit Care Med 150:184-193

59. Curley MA, Thompson JE, Arnold JH (2000) The effects of early and repeated prone positioning in pediatric patients with acute lung injury. Chest 118:156-163

60. Ranieri VM, Suter PM, Tortorella C et al (1999) Effect of mechanical ventilation on inflammatory mediators in patients with acute respiratory distress syndrome: A randomized controlled trial. JAMA 282:54-61

61. Zobel G, Kuttnig M, Trop M et al (1990) A respiratory severity index for children with ARDS. Clin Intensive Care 1:17-21

62. Timmons OD, Havens PL, Fackler FC et al (1995) Predicting death in pediatric patients with acute respiratory failure. Chest 108:789-797 